Author affiliations appear at the end of this article.

Published online ahead of print at www.jco.org on September 14, 2015.

Written on behalf of the SAR-3007 investigators.

Processed as a Rapid Communication manuscript.

Supported by Janssen Pharmaceuticals and supported in part by the Adelson Medical Research Foundation (G.D.D.)

Authors' disclosures of potential conflicts of interest are found in the article online at www.jco.org. Author contributions are found at the end of this article.

Clinical trial information: NCT01343277.

Corresponding author: George D. Demetri, MD, Ludwig Center at Harvard, Harvard Medical School, and Center for Sarcoma and Bone Oncology, DanaFarber Cancer Institute, 450 Brookline Ave, Boston, MA 02215; e-mail: george_demetri@dfci.harvard.edu.

(C) 2015 by American Society of Clinical Oncology

0732-183X/16/3408w-786w/\$20.00 DOI: 10.1200/JCO 2015.62 .4734

\title{
Efficacy and Safety of Trabectedin or Dacarbazine for Metastatic Liposarcoma or Leiomyosarcoma After Failure of Conventional Chemotherapy: Results of a Phase III Randomized Multicenter Clinical Trial
}

George D. Demetri, Margaret von Mehren, Robin L. Jones, Martee L. Hensley, Scott M. Schuetze, Arthur Staddon, Mohammed Milhem, Anthony Elias, Kristen Ganjoo, Hussein Tawbi, Brian A. Van Tine, Alexander Spira, Andrew Dean, Nushmia Z. Khokhar, Youn Choi Park, Roland E. Knoblauch, Trilok V. Parekh, Robert G. Maki, and Shreyaskumar R. Patel

See accompanying editorial on page 769

$\begin{array}{llllllll}\text { A } & \text { B } & \text { S } & \text { T } & \text { R } & \text { A } & \text { C } & \text { T }\end{array}$

\section{Purpose}

This multicenter study, to our knowledge, is the first phase III trial to compare trabectedin versus dacarbazine in patients with advanced liposarcoma or leiomyosarcoma after prior therapy with an anthracycline and at least one additional systemic regimen.

\section{Patients and Methods}

Patients were randomly assigned in a 2:1 ratio to receive trabectedin or dacarbazine intravenously every 3 weeks. The primary end point was overall survival (OS), secondary end points were disease control-progression-free survival (PFS), time to progression, objective response rate, and duration of response-as well as safety and patient-reported symptom scoring.

\section{Results}

A total of 518 patients were enrolled and randomly assigned to either trabectedin $(\mathrm{n}=345$ ) or dacarbazine ( $n=173$ ). In the final analysis of PFS, trabectedin administration resulted in a $45 \%$ reduction in the risk of disease progression or death compared with dacarbazine (median PFS for trabectedin $v$ dacarbazine, 4.2 v1.5 months; hazard ratio, 0.55; $P<.001$ ); benefits were observed across all preplanned subgroup analyses. The interim analysis of OS (64\% censored) demonstrated a $13 \%$ reduction in risk of death in the trabectedin arm compared with dacarbazine (median OS for trabectedin $v$ dacarbazine, $12.4 \mathrm{v}$ 12.9 months; hazard ratio, $0.87 ; P=.37)$. The safety profiles were consistent with the well-characterized toxicities of both agents, and the most common grade 3 to 4 adverse effects were myelosuppression and transient elevation of transaminases in the trabectedin arm.

\section{Conclusion}

Trabectedin demonstrates superior disease control versus conventional dacarbazine in patients who have advanced liposarcoma and leiomyosarcoma after they experience failure of prior chemotherapy. Because disease control in advanced sarcomas is a clinically relevant end point, this study supports the activity of trabectedin for patients with these malignancies.

\section{J Clin Oncol 34:786-793. (c) 2015 by American Society of Clinical Oncology}

\section{INTRODUCTION}

After GI stromal tumors, leiomyosarcomas and liposarcomas are the most common subtypes of soft tissue sarcomas (STS), a heterogeneous group of malignancies that arise from tissues of mesenchymal origin and together compose approximately $1 \%$ of all solid tumors. ${ }^{1,2}$

The prognosis for patients with advanced or metastatic STS is poor, with an estimated median survival of 12 to 15 months. ${ }^{3-5}$ Treatment is palliative in nature, and the goal is delay of the progression and severe morbidity that can arise when tumor growth compromises organ function. ${ }^{6}$ Initial therapy for patients with STS that is unresectable for cure typically includes cytotoxic chemotherapy that is most commonly anthracycline based (mainly doxorubicin) or gemcitabine based. ${ }^{7,8}$ Other chemotherapeutic agents, including dacarbazine, ifosfamide, and unapproved analogs, have been investigated. ${ }^{9-13}$ In metastatic STS, combination chemotherapy with dose-intensive doxorubicin 
plus ifosfamide improves response rates and disease control compared with doxorubicin alone but with increased severe toxicities and without overall survival benefit. ${ }^{5}$ The activities of single-agent dacarbazine and ifosfamide in this clinical setting have been used by the European Organization for Research and Treatment of Cancer as a reference to assess the activity of novel agents in STS (3- and 6-month progression-free rates [PFRs] of 39\% and 14\%, respectively). ${ }^{14}$ These thresholds have been used to assess the activity of trabectedin in phase II studies ${ }^{15}$ and to identify the target population for the pivotal phase III study of pazopanib. ${ }^{16,17}$

Trabectedin, a marine-derived drug, has a complex mechanism of action that affects key cell biology processes in tumor cells and the tumor microenvironment through direct effects on tumor-associated macrophages and tissue-resident histiocytes. ${ }^{18-20}$ It binds to the minor groove of DNA, which thereby affects the function of DNA binding proteins, including transcription factors and DNA repair machinery, to result in perturbation of the cell cycle and induction of p53-independent apoptosis. ${ }^{21,22}$ In several phase II trials, trabectedin exhibited activity in patients with metastatic STS, ${ }^{23-25}$ and a randomized trial to test two different doses and schedules of trabectedin led to the first regulatory approval in $2007 .{ }^{15}$ The present multicenter study was conducted to compare the efficacy and safety of trabectedin versus dacarbazine in a randomized phase III trial in patients with advanced liposarcoma or leiomyosarcoma.

\section{PATIENTS AND METHODS}

\section{Patients}

Patients were eligible if they were age 15 years or older; had unresectable, locally advanced or metastatic liposarcoma or leiomyosarcomas; and were previously treated with at least either a combination of an anthracycline and ifosfamide or an anthracycline plus one or more additional cytotoxic chemotherapy regimen(s). Patients required adequate bone marrow, renal, and liver functions, and an Eastern Cooperative Oncology Group performance status score of 1 or lower. Exclusion criteria included known CNS metastasis, myocardial infarct within 6 months before enrollment, and New York Heart Association class II or greater heart failure. Review boards at all participating institutions approved the study, which was conducted according to the Declaration of Helsinki, the
International Conference on Harmonisation, and the Guidelines for Good Clinical Practice. All patients provided written informed consent to participate on the study.

\section{Study Design and Treatment}

This phase III trial (NCT01343277, also coded as ET743-SAR-3007) is a randomized, open-label, active-controlled, parallel-group, multicenter study implemented at 85 sites in four countries. Patients were randomly assigned in a 2:1 ratio to receive either trabectedin at a starting dose of $1.5 \mathrm{mg} / \mathrm{m}^{2}$ as a 24 -hour intravenous (IV) infusion or dacarbazine at a starting dose of $1 \mathrm{~g} / \mathrm{m}^{2}$ as a 20 - to 120 -minute IV infusion. Study drug was administered on day 1 of each 21-day treatment cycle. All trabectedin doses were administered via central IV access after premedication with dexamethasone $20 \mathrm{mg}$ IV. Criteria for dose reductions and dose delays, in case of treatment-associated toxicities, were standardized in the protocol.

The primary study end point was overall survival (OS); secondary end points assessed disease control and included progression-free survival (PFS), time to progression, objective response rate (ORR), and duration of response (DOR). The end points of clinical benefit rate ${ }^{26}$ (CBR; defined as the sum of complete responses + partial responses $[\mathrm{PR}]+$ stable disease for at least 18 weeks) and duration of stable disease were added to the statistical analysis plan as preplanned analyses to describe those patients who experienced prolonged disease control.

The study was designed with a preplanned interim analysis of the primary end point of OS, which was to occur concurrently with the final analysis of PFS, at 188 death events. The clinical cutoff date of September 16,2013 , was prospectively determined on the basis of anticipation of the required number of death events.

\section{Assessments}

Monitoring of study participant survival was performed and used to calculate OS. Investigators assessed tumor response by radiographic imaging of the chest, abdomen, and pelvis every 6 weeks for the first 36 weeks on study and every 9 weeks thereafter until disease progression, subsequent anticancer therapy, or patient death occurred. The PFS end point was validated through an audit by independent radiologists, who were blinded to treatment assignment and who assessed radiographic PFS (rPFS) in a subset of approximately $60 \%$ of the study population. Safety assessments were based on observed adverse events, clinical laboratory tests, vital sign measurement, physical examination, cardiac function (using multigated acquisition scan or echocardiogram), and concomitant medication use.

\begin{tabular}{|c|c|c|c|c|c|}
\hline \multicolumn{6}{|c|}{$\begin{array}{l}\text { Randomly allocated } \\
\qquad(N=518)\end{array}$} \\
\hline $\begin{array}{l}\text { Allocated to dacarbazine } \\
\text { Received dacarbazine } \\
\text { Did not receive dacarbazine }\end{array}$ & \multicolumn{2}{|c|}{$\begin{array}{r}(\mathrm{n}=173) \\
(\mathrm{n}=155) \\
(\mathrm{n}=18)\end{array}$} & \multicolumn{2}{|c|}{$\begin{array}{l}\text { Allocated to trabectedin } \\
\text { Received trabectedin } \\
\text { Did not receive trabectedin }\end{array}$} & $\begin{array}{r}(n=345) \\
(n=340) \\
(n=5)\end{array}$ \\
\hline $\begin{array}{l}\text { Discontinued dacarb } \\
\text { Disease progressio } \\
\text { Adverse event } \\
\text { Withdrew consent } \\
\text { Died } \\
\text { Other }\end{array}$ & $\begin{array}{l}\text { bazine } \\
\text { on }\end{array}$ & $\begin{array}{r}(\mathrm{n}=132) \\
(\mathrm{n}=106) \\
(\mathrm{n}=11) \\
(\mathrm{n}=11) \\
(\mathrm{n}=1) \\
(\mathrm{n}=3)\end{array}$ & $\begin{array}{l}\text { Discontinued trabectedin } \\
\text { Disease progression } \\
\text { Adverse event } \\
\text { Withdrew consent } \\
\text { Died } \\
\text { Other }\end{array}$ & $\begin{array}{r}(n=244) \\
(n=186) \\
(n=34) \\
(n=11) \\
(n=9) \\
(n=4)\end{array}$ & \\
\hline Continued dacarbazine treatment & \multicolumn{2}{|c|}{$(n=23)$} & \multicolumn{2}{|c|}{ Continued trabectedin treatment } & $(n=96)$ \\
\hline $\begin{array}{l}\text { Analyzed for progression-free } \\
\text { survival and overall survival } \\
\text { Included in safety analysis }\end{array}$ & \multicolumn{2}{|c|}{$\begin{array}{l}(n=173) \\
(n=155)\end{array}$} & \multicolumn{2}{|c|}{$\begin{array}{l}\text { Analyzed for progression-free } \\
\text { survival and overall survival } \\
\text { Included in safety analysis }\end{array}$} & $\begin{array}{l}(\mathrm{n}=345) \\
(\mathrm{n}=340)\end{array}$ \\
\hline
\end{tabular}

Fig 1. CONSORT diagram. 


\section{Statistical Analyses}

The primary statistical methodology for comparison of treatment effectiveness for OS, PFS, and DOR was the unstratified log-rank test. A Cox proportional hazard model was used to examine the effect of the prognostic factors. The statistical methodology for ORR and CBR was Fisher's exact test. To detect a difference between a median OS of 10 months in the dacarbazine group and a median OS of 13.5 months in the trabectedin group (hazard ratio [HR], 0.74) at an overall two-sided significance level of .05 with a power of $80 \%$ required 376 events. A sample size of 570 patients was planned with an interim analysis for OS after $50 \%$ of events. The cumulative $\alpha$ spent was to be .003 and .047 for the interim and final OS analyses, respectively. This study used a group sequential method with the O'Brien-Fleming boundaries, as implemented by the Lan-DeMets $\alpha$ spending function.

One analysis of PFS was planned at the time of the OS interim analysis after a projected 331 PFS events, which provided at least $90 \%$ power to detect an HR of 0.667 (median PFS for dacarbazine $\mathrm{v}$ trabectedin arms, $2.50 \vee 3.75$ months, respectively) with a two-sided significance level of 05 . Final PFS and ORR data, after recommendations of the independent data monitoring committee, were submitted for regulatory consideration while the study continued toward the final analysis for OS. The results of the overall estimate of HR for rPFS, which were based on an independent audit, were calculated as proposed by the method of Dodd. ${ }^{27}$ The upper limit for the $95 \%$ CI was compared with 1 .

\section{RESULTS}

\section{Patients and Treatment}

Between May 27, 2011, and the September 16, 2013, clinical cutoff for the interim analysis of the primary end point of OS, 518 of 570 planned patients were randomly assigned to receive either trabectedin $(\mathrm{n}=345)$ or dacarbazine $(\mathrm{n}=173$; Fig 1$)$ and are included in this interim analysis. Enrollment was ongoing at the time of the clinical cutoff. Baseline demographic and disease characteristics were well balanced (Table 1). The study population was heavily pretreated; $88 \%$ had at least two previous lines of systemic therapy, greater than $90 \%$ had previous surgery, and 50\% had prior radiotherapy. The median time from last disease progression was less than 1 month in both treatment groups ( 0.85 v 0.82 months, respectively), and a majority (58\%) reported progressive disease as the best response to their previous line of therapy.

\section{Time on Study Treatments}

At the time of interim analysis, the proportion of patients in the trabectedin arm still receiving study treatment was nearly double that in the dacarbazine arm (28\% $v 15 \%$, respectively). Disease progression was the most common reason for discontinuation of study treatment regardless of treatment group (trabectedin $v$ dacarbazine, 55\% v 68\%). Discontinuation resulting from toxicity, including adverse events and death, occurred in $12.6 \%$ and $7.7 \%$ of the trabectedin and dacarbazine groups, respectively. Withdrawal of consent occurred twice as frequently in the dacarbazine group, by $3.2 \%$ patients in the trabectedin group versus by $7.1 \%$ in the dacarbazine group.

The median number of cycles received in the trabectedin group was twice that of the dacarbazine group ( $4 v 2$ cycles, respectively), and increased exposure rates were noted at both six cycles $(34 \% v 17 \%$, respectively) and 12 cycles ( $10 \% \vee 2 \%$, respectively). Cycle delays or dose reductions were reported in $57 \%$ and $35 \%$ of patients in the
Table 1. Baseline Demographic and Disease Characteristics

\begin{tabular}{|c|c|c|}
\hline \multirow[b]{2}{*}{ Variable } & \multicolumn{2}{|c|}{ No. (\%) of Patients } \\
\hline & $\begin{array}{l}\text { Trabectedin } \\
(n=345)\end{array}$ & $\begin{array}{l}\text { Dacarbazine } \\
(\mathrm{n}=173)\end{array}$ \\
\hline \multicolumn{3}{|l|}{ Age, years } \\
\hline Median (range) & $57(18.0-81.0)$ & $56(17.0-79.0)$ \\
\hline \multicolumn{3}{|l|}{ Sex } \\
\hline Male & $107(31)$ & $47(27)$ \\
\hline Female & $238(69)$ & $126(73)$ \\
\hline \multicolumn{3}{|l|}{ Baseline BMI, kg/m² } \\
\hline Median (range) & $28.21(14.5-78.1)$ & $27.05(13.3-66.7)$ \\
\hline \multicolumn{3}{|l|}{ Histology } \\
\hline Leiomyosarcoma & $252(73)$ & $126(73)$ \\
\hline Uterine & $134(39)$ & $78(45)$ \\
\hline Nonuterine & $118(34)$ & $48(28)$ \\
\hline Liposarcoma & $93(27)$ & $47(27)$ \\
\hline Myxoid \pm round cell & $38(11)$ & $19(11)$ \\
\hline Pleomorphic & $10(3)$ & $3(2)$ \\
\hline Dedifferentiated & $45(13)$ & $25(15)$ \\
\hline \multicolumn{3}{|l|}{$\begin{array}{l}\text { Baseline ECOG performance } \\
\text { status score }\end{array}$} \\
\hline 0 & $171(50)$ & $86(50)$ \\
\hline 1 & $174(50)$ & $87(50)$ \\
\hline \multicolumn{3}{|l|}{ Lines of prior chemotherapy } \\
\hline 1 & $38(11)$ & $23(13)$ \\
\hline 2 & $160(46)$ & $75(43)$ \\
\hline 3 & $87(25)$ & $43(25)$ \\
\hline 4 & $37(11)$ & $21(12)$ \\
\hline$>4$ & $23(7)$ & $11(6)$ \\
\hline \multicolumn{3}{|l|}{$\begin{array}{l}\text { Best response to last line of } \\
\text { previous chemotherapy }\end{array}$} \\
\hline Complete response & $4(1)$ & $3(2)$ \\
\hline Partial response & $28(8)$ & $14(8)$ \\
\hline No change (stable disease) & 114 (33) & $51(30)$ \\
\hline Progression of disease & $198(57)$ & $103(60)$ \\
\hline Unknown/missing & $1(0)$ & $2(1)$ \\
\hline \multicolumn{3}{|l|}{$\begin{array}{l}\text { Previous surgery for } \\
\text { malignancy }\end{array}$} \\
\hline Yes & $327(95)$ & $158(91)$ \\
\hline No & $18(5)$ & $15(9)$ \\
\hline \multicolumn{3}{|l|}{$\begin{array}{l}\text { Previous radiotherapy for } \\
\text { malignancy }\end{array}$} \\
\hline Yes & $176(51)$ & $80(46)$ \\
\hline No & 169 (49) & $93(54)$ \\
\hline \multicolumn{3}{|l|}{$\begin{array}{l}\text { Time from initial diagnosis } \\
\text { to random assignment, } \\
\text { months }\end{array}$} \\
\hline Median (range) & $33.94(2.5-318.5)$ & $27.10(1.6-267.1)$ \\
\hline \multicolumn{3}{|l|}{$\begin{array}{l}\text { Time from last disease } \\
\text { progression to random } \\
\text { assignment, months }\end{array}$} \\
\hline Median (range) & $0.85(0.0-13.7)$ & $0.82(0.1-9.8)$ \\
\hline $\begin{array}{l}\text { NOTE. Percentages were calc } \\
\text { assigned to each treatment gro } \\
\text { Abbreviations: BMI, body mas } \\
\text { Group. }\end{array}$ & $\begin{array}{l}d \text { with the numbe } \\
\text { the denominator. } \\
\text { x; ECOG, Eastern }\end{array}$ & $\begin{array}{l}\text { patients randomly } \\
\text { pperative Oncology }\end{array}$ \\
\hline
\end{tabular}

trabectedin group, respectively, compared with $40 \%$ and $10 \%$ of patients in the dacarbazine group (Appendix Table Al, online only).

\section{Efficacy}

The final analysis of PFS, performed after 329 PFS events, showed that treatment with trabectedin resulted in a $45 \%$ reduction in the risk of disease progression or death compared with dacarbazine (HR, 0.55; $95 \%$ CI, 0.44 to $0.70 ; P<.001$; Fig $2 \mathrm{~A}$ ). Improved disease control by trabectedin was discernible at the time of the first planned disease 


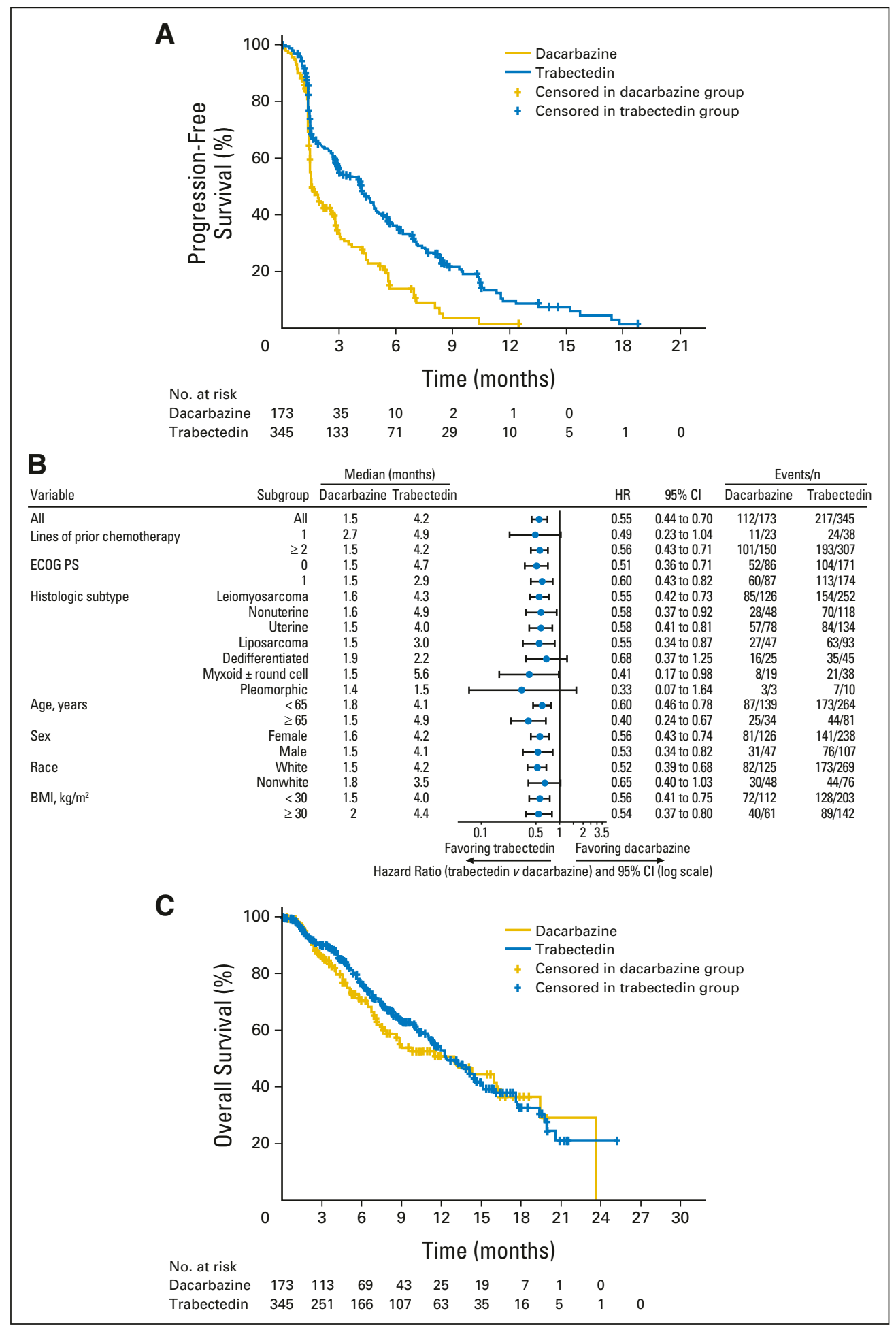

Fig 2. Kaplan-Meier estimates of progression-free survival, subgroup analyses, and overall survival at the interim analysis. (A) Progression-free survival; (B) subgroup analysis (hazard ratios [HRs] and 95\% Cls) of progression-free survival; and (C) overall survival. HR was calculated as the hazard in the trabectedin treatment group divided by the hazard in the dacarbazine treatment group. BMI, body mass index.

assessment (6 weeks), which led to an improved median PFS in the trabectedin group (4.2 months $v 1.5$ months with dacarbazine). PFRs at 3 and 6 months were $56 \%$ and $37 \%$ in the trabectedin arm versus $34 \%$ and $14 \%$ in the dacarbazine arm. The PFS treatment benefit with trabectedin was consistently observed across all 19 preplanned subgroups examined in sensitivity analyses (Fig 2B), and equivalent benefits were observed across the two sarcoma subtypes (HR, 0.55 each for patients with leiomyosarcoma and for patients with liposarcoma).

To validate the investigator assessment of PFS, an audit was conducted by independent radiologists who were blinded to treatment assignment. The rPFS of the entire study population, and of the audited and unaudited subgroups, was calculated by using 


\begin{tabular}{|c|c|c|c|c|c|c|}
\hline \multirow[b]{2}{*}{ Variable } & \multicolumn{6}{|c|}{ Survival Measure } \\
\hline & $\begin{array}{l}\text { PFS-INV } \\
(n=518)\end{array}$ & $\begin{array}{l}\text { rPFS-INV } \\
(n=518)\end{array}$ & $\begin{array}{c}\text { rPFS-INV } \\
\text { (audited subset; } \mathrm{n}=304 \text { ) }\end{array}$ & $\begin{array}{c}\text { rPFS-INV } \\
\text { (unaudited subset; } n=214 \text { ) }\end{array}$ & $\begin{array}{c}\text { rPFS-IR } \\
\text { (audited subset; } \mathrm{n}=304 \text { ) }\end{array}$ & $\begin{array}{c}\text { rPFS-IR } \\
\text { (overall estimate) }\end{array}$ \\
\hline$H R^{*}$ & 0.55 & 0.57 & 0.58 & 0.54 & 0.55 & 0.54 \\
\hline $95 \% \mathrm{Cl}$ & 0.44 to 0.70 & 0.45 to 0.72 & 0.43 to 0.79 & 0.37 to 0.80 & 0.40 to 0.75 & 0.41 to 0.71 \\
\hline
\end{tabular}

investigator assessment; then, the rPFS was calculated for the audited subgroup by using the independent radiologists' assessments (Table 2). The independent assessment of the rPFS of the audited subset (HR, 0.55) was used to provide an estimate of the HR for the rPFS of the entire population by using an adaptation of a previously reported method ${ }^{27}$ (HR, $0.54 ; 95 \%$ CI, 0.41 to 0.71 ), which was consistent with the investigator assessment.

Best responses experienced by both treatment groups, as well as their durations, are summarized in Table 3. There were no complete responses in either treatment group. PRs were more frequently observed within the trabectedin group (ORR, 9.9\% $v$ $6.9 \% ; P=.33$ ). The median DOR within the trabectedin group was approximately $50 \%$ greater than in the dacarbazine group (6.5 v 4.2 months, respectively; $P<.14$ ). Stable disease as best response was more frequently achieved in the trabectedin group $(51 \% v$ $35 \%)$, and the median duration of stable disease was significantly improved in the trabectedin arm $(6.0 v 4.2$ months; $P<.001)$. The clinical benefit rate, which reflects both objective disease response and durable stable disease, was significantly higher in the trabectedin group (34\% v 19\%; $P<.001$; Table 3$)$.

The interim analysis occurred as planned at $50 \%$ of the total events required for the final analysis of OS (ie, 189 death events). The median duration of survival follow-up time was 8.6 months. Although the OS data at this interim analysis were highly censored (64\%), the results favored the trabectedin group, with an overall 13\% reduction in risk of death (median OS of trabectedin $v$ dacarbazine, 12.4 months $v 12.9$ months; HR, $0.87 ; P=.37$; Fig 2 C). Subsequent anticancer therapy was less frequently used in the trabectedin arm ( $47 \% \vee 56 \%$, respectively) and occurred significantly later after study entry (median time to initiation from random assignment for trabectedin versus dacarbazine, $6.9 v 3.7$ months; $\mathrm{HR}, 0.47$; 95\% CI, 0.36 to $0.61 ; P<.001)$. The most frequently used subsequent therapy in both arms (trabectedin $v$ dacarbazine) was pazopanib ( $18 \% v 28 \%$, respectively), which was followed by radiation (10\% $v 15 \%$, respectively), gemcitabine ( $9 \% v 15 \%$, respectively), and dacarbazine (17\% v6\%, respectively; Table 4).

\section{Safety}

The adverse events of the study were consistent with the wellcharacterized safety and toxicity profiles of both study drugs. The most common adverse events were predominantly of grade 1 to 2 severity (Table 5). Grade 3 to 4 toxicities were primarily observed in laboratory-based measures of myelosuppressive toxicity (in both treatment groups) and transient transaminase elevations (in the trabectedin group). Less often, grade 3 to 4 creatine phosphokinase elevations were seen with trabectedin treatment $(5.3 \% v 0.6 \%$ in the dacarbazine group), and $1.2 \%$ of patients who received trabectedin experienced rhabdomyolysis.

The incidence of patients who died within 60 days of the first dose of study drug was similar in both treatment arms $(7.1 \% \mathrm{v}$ $5.8 \%$ in trabectedin $v$ dacarbazine arms, respectively), whereas treatment-related deaths $(\mathrm{n}=7 ; 2.1 \%)$ were only reported in the trabectedin group. These deaths were related to sepsis/septic shock $(\mathrm{n}=3)$, rhabdomyolysis/sepsis $(\mathrm{n}=1)$, renal failure $(\mathrm{n}=1)$, renal failure/cardiac arrest $(n=1)$, or multiorgan failure $(n=1)$.

\section{DISCUSSION}

This multicenter, randomized, international, phase III clinical trial confirms prior experience in smaller trials that documented the efficacy of trabectedin in the control of advanced STS after failure of prior cytotoxic chemotherapy. The patients studied were heavily pretreated, having experienced failure of previous systemic therapy, surgery, and radiation therapy, and they had rapidly progressing disease. Within

\begin{tabular}{|c|c|c|c|c|}
\hline PFS, months & 4.2 & 1.5 & 0.55 (0.44 to 0.70$)$ & $<.001$ \\
\hline No. (\%) of ORR & $34(9.9)$ & $12(6.9)$ & $1.47(0.72$ to 3.2$)$ & .33 \\
\hline DOR, months & 6.5 & 4.2 & $0.47(0.17$ to 1.32$)$ & .14 \\
\hline No. (\%) with SD as best response & $177(51)$ & $60(35)$ & - & - \\
\hline
\end{tabular}




\begin{tabular}{|lcc|}
\hline \multicolumn{3}{|c|}{ Table 4. Selected Subsequent Anticancer Therapy } \\
\hline & \multicolumn{2}{c|}{ No. (\%) of Patients } \\
\cline { 2 - 3 } & $\begin{array}{c}\text { Trabectedin } \\
(n=345)\end{array}$ & $\begin{array}{c}\text { Dacarbazine } \\
(n=173)\end{array}$ \\
\hline Total with subsequent anticancer chemotherapy & $162(47)$ & $97(56)$ \\
Pazopanib & $63(18)$ & $48(28)$ \\
Dacarbazine & $60(17)$ & $11(6)$ \\
Radiation & $35(10)$ & $25(15)$ \\
Gemcitabine & $30(9)$ & $25(15)$ \\
Surgery & $23(7)$ & $17(10)$ \\
Docetaxel & $19(6)$ & $21(12)$ \\
Ifosfamide & $7(2)$ & $10(6)$ \\
Doxorubicin & $9(3)$ & $5(3)$ \\
Eribulin & $9(3)$ & $1(1)$ \\
Trabectedin & $1(<1)$ & $4(2)$ \\
\hline $\begin{array}{l}\text { NOTE. Subsequent anticancer therapies that were used for at least } 5 \% \text { of } \\
\text { patients in either treatment group were included. In addition, doxorubicin, eri- } \\
\text { bulin, and trabectedin were also included on the basis of their previously } \\
\text { demonstrated activities. }\end{array}$ \\
\hline
\end{tabular}

this high-risk population, trabectedin administration resulted in a statistically significant $45 \%$ reduction in the risk of disease progression or death versus the active control therapy, dacarbazine $(P<.001)$. This benefit in disease control was observed regardless of disease histology; previous lines of systemic therapy; or clinical considerations, such as age, sex, ethnicity, or baseline performance status. Of note, the greatest increase in median PFS (5.6 months $v 1.5$ months with trabectedin $v$ dacarbazine, respectively) was observed within the myxoid/round cell liposarcoma subgroup (Fig 2B), which is consistent with the early identification of this uniquely sensitive STS subtype $^{25,28}$ and similar to a recent report of trabectedin activity in patients with translocation-related sarcomas. ${ }^{29,30}$ This is also highly consistent with the proposed action of trabectedin as a direct inhibitor of the chimeric FUS-CHOP translocation-generated oncoprotein that has transcriptional regulatory activity in these tumors. ${ }^{31-33}$

The benefit of trabectedin versus dacarbazine treatment was also supported by other secondary end points, with improvements in both the ORR (9.9\% $v 6.9 \%$, respectively), and the median duration of responses ( $6.5 v 4.2$ months, respectively). Importantly, the majority of patients who benefited from trabectedin experienced stable disease as their best response, at an increased rate than that observed with dacarbazine (51\% v 35\%) and for significantly increased durations. The CBR, which included objective disease shrinkage (which consisted of PRs in this trial) and durable stable disease (ie, $>18$ weeks in duration), also documents the anticancer activity of trabectedin, because nearly twice the proportion of patients who received trabectedin versus those who received dacarbazine achieved this end point in this randomized study (34\% $v 19 \%$, respectively). The therapeutic benefit of continued disease control with extended trabectedin dosing beyond six cycles has been reported in a recent study as well. ${ }^{34}$

The safety and tolerability of these study drugs were consistent with extensive prior experience and reports. ${ }^{11,12,15,35}$ Laboratory abnormalities were the most frequently reported grade 3 to 4 adverse events in this study; were generally transient and noncumulative; and were managed by dose delays, reductions, supportive care, and, if required, treatment discontinuations. Although this study demonstrates that toxicity was increased in the trabectedin arm, trabectedin is regarded as a generally well-tolerated agent relative to other sarcoma treatment options, with low rates of mucositis and alopecia and no cumulative toxicities that limit treatment duration. Consistent with this profile, a greater proportion of patients in the trabectedin arm than in the dacarbazine arm were able to receive prolonged courses of therapy. Extensive clinical experience with trabectedin outside the United States in standard practice has supported its reputation as a generally well-tolerated agent with no cumulative toxicities, which was again demonstrated in this study. ${ }^{35-38}$

\begin{tabular}{|c|c|c|c|c|c|c|}
\hline \multirow[b]{3}{*}{ Adverse Event } & \multicolumn{6}{|c|}{ No. (\%) Adverse Events by Treatment and Grade } \\
\hline & \multicolumn{3}{|c|}{ Trabectedin $(n=340)$} & \multicolumn{3}{|c|}{ Dacarbazine $(n=155)$} \\
\hline & All Grades & Grade 3 & Grade 4 & All Grades & Grade 3 & Grade 4 \\
\hline Nausea & $247(73)$ & $18(5)$ & 0 & $76(49)$ & $3(2)$ & 0 \\
\hline Fatigue & $228(67)$ & $20(6)$ & 0 & $79(51)$ & $2(1)$ & $1(1)$ \\
\hline Neutropenia & $165(49)$ & $70(21)$ & $56(16)$ & $45(29)$ & $17(11)$ & $15(10)$ \\
\hline Alanine aminotransferase increased & $154(45)$ & $85(25)$ & $4(1)$ & $9(6)$ & $1(1)$ & 0 \\
\hline Vomiting & $149(44)$ & $16(5)$ & 0 & $33(21)$ & $2(1)$ & 0 \\
\hline Anemia & $134(39)$ & 49 (14) & 0 & $45(29)$ & $17(11)$ & $1(1)$ \\
\hline Constipation & $121(36)$ & $3(1)$ & 0 & $44(28)$ & 0 & 0 \\
\hline Aspartate aminotransferase increased & $120(35)$ & $40(12)$ & $4(1)$ & $8(5)$ & 0 & 0 \\
\hline Decreased appetite & $116(34)$ & $7(2)$ & 0 & $31(20)$ & 0 & $1(1)$ \\
\hline Diarrhea & $115(34)$ & $6(2)$ & 0 & $35(23)$ & 0 & 0 \\
\hline Thrombocytopenia & $101(30)$ & $27(8)$ & $31(9)$ & $56(36)$ & $15(10)$ & $13(8)$ \\
\hline Dyspnea & $84(25)$ & $12(4)$ & $1(<1)$ & $30(19)$ & $1(1)$ & 0 \\
\hline Peripheral edema & $83(24)$ & $3(1)$ & 0 & $21(14)$ & $1(1)$ & 0 \\
\hline Headache & $78(23)$ & $1(<1)$ & 0 & $29(19)$ & 0 & 0 \\
\hline Blood alkaline phosphatase increased & $69(20)$ & $5(1)$ & 0 & $11(7)$ & 0 & 0 \\
\hline Cough & $61(18)$ & $1(<1)$ & 0 & $32(21)$ & 0 & 0 \\
\hline
\end{tabular}


The 3- and 6-month PFRs observed in this study provide historical context to these results, which are consistent with earlier studies with both agents. The 3- and 6-month PFRs of dacarbazine (34\% and $14 \%$, respectively) were consistent with the European Organization for Research and Treatment of Cancer criteria established to define active agents in unselected STS (39\% and 14\%, respectively) and with a recent phase II study in patients with unselected STS. ${ }^{12}$ This level of activity across multiple studies suggests that the activity of dacarbazine is similar across sarcoma study populations (ie, liposarcoma or leiomyosarcoma with selected and unselected histologies) and justifies its selection as the active comparator in this study.

In this study, 3- and 6-month PFRs of trabectedin (56\% and 37\%, respectively) confirm the higher level of anticancer activity of trabectedin in patients with leiomyosarcoma and liposarcoma, which was also observed in a prior randomized, phase II study (52\% and 36\%, respectively). ${ }^{15}$ The confirmation of activity within this patient population provides an additional treatment option for patients who have limited systemic options, given the lower ifosfamide efficacy in patients with leiomyosarcoma ${ }^{5,39}$ and the relative lack of efficacy of pazopanib in patients with liposarcoma. ${ }^{16}$ Furthermore, the favorable efficacy observed in patients older than 65 years, with a safety profile similar to that observed in younger patients (data not shown), confirms the results of earlier analyses ${ }^{40}$ that suggest that trabectedin is an important treatment option for a group of patients who are often excluded from treatment with doxorubicin-based regimens. ${ }^{5}$

The interim analysis of OS, the primary end point of this study, demonstrated a statistically nonsignificant $13 \%$ reduction in risk of death that favored the trabectedin group. Of note, the median OS in the dacarbazine arm was statistically equivalent to the trabectedin group and exceeded the predefined statistical assumption of 10 months; this may reflect the use of subsequent therapies, including pazopanib, which was approved by regulatory agencies for STS during the conduct of this trial. Although the study continued per protocol for the final analysis of OS, the results of two recently reported phase III studies have illustrated the difficulty in prolonging
OS, despite robust improvements in PFS, even when the control arm involves a placebo. ${ }^{5,17}$ Given the historical difficulty in demonstrating OS improvement, the clinical documentation of disease control, measured as PFS and CBR, has been proposed as a measure of clinically relevant efficacy in advanced sarcomas. ${ }^{26}$ The results of this large, randomized trial support the activity of trabectedin as an effective anticancer agent in this population of patients who have rare but life-threatening malignancies.

\section{AUTHORS' DISCLOSURES OF POTENTIAL CONFLICTS OF INTEREST}

Disclosures provided by the authors are available with this article at www.jco.org.

\section{AUTHOR CONTRIBUTIONS}

Conception and design: George D. Demetri, Margaret von Mehren, Nushmia Z. Khokhar, Youn Choi Park, Roland E. Knoblauch, Trilok V. Parekh, Robert G. Maki, Shreyaskumar R. Patel

Provision of study materials or patients: George D. Demetri, Margaret von Mehren, Robin L. Jones, Martee L. Hensley, Scott M. Schuetze, Arthur Staddon, Mohammed Milhem, Anthony Elias, Kristen Ganjoo, Hussein Tawbi, Brian A. Van Tine, Alexander Spira, Andrew Dean, Shreyaskumar R. Patel

Collection and assembly of data: George D. Demetri, Margaret von Mehren, Robin L. Jones, Martee L. Hensley, Scott M. Schuetze, Arthur Staddon, Mohammed Milhem, Anthony Elias, Kristen Ganjoo, Hussein Tawbi, Brian A. Van Tine, Alexander Spira, Andrew Dean, Shreyaskumar R. Patel

Data analysis and interpretation: George D. Demetri, Margaret von Mehren, Nushmia Z. Khokhar, Youn Choi Park, Roland E. Knoblauch, Trilok V. Parekh, Robert G. Maki, Shreyaskumar R. Patel

Manuscript writing: All authors

Final approval of manuscript: All authors

\section{REFERENCES}

1. Van Glabbeke M, van Oosterom AT, Oosterhuis JW, et al: Prognostic factors for the outcome of chemotherapy in advanced soft tissue sarcoma: An analysis of 2,185 patients treated with anthracyclinecontaining first-line regimens-A European Organization for Research and Treatment of Cancer Soft Tissue and Bone Sarcoma Group study. J Clin Oncol 17: 150-157, 1999

2. Clark MA, Fisher $C$, Judson I, et al: Soft-tissue sarcomas in adults. N Engl J Med 353:701-711, 2005

3. Santoro A, Tursz T, Mouridsen H, et al: Doxorubicin versus CYVADIC versus doxorubicin plus ifosfamide in first-line treatment of advanced soft tissue sarcomas: A randomized study of the European Organization for Research and Treatment of Cancer Soft Tissue and Bone Sarcoma Group. J Clin Oncol 13:1537-1545, 1995

4. Patel SR, Vadhan-Raj S, Burgess MA, et al: Results of two consecutive trials of dose-intensive chemotherapy with doxorubicin and ifosfamide in patients with sarcomas. Am J Clin Oncol 21:317-321, 1998

5. Judson I, Verweij J, Gelderblom $H$, et al: Doxorubicin alone versus intensified doxorubicin plus ifosfamide for first-line treatment of advanced or metastatic soft-tissue sarcoma: A randomized controlled phase III trial. Lancet Oncol 15:415-423, 2014

6. Schoffski P, Cornillie J, Wozniak A, et al: Soft tissue sarcoma: An update on systemic treatment options for patients with advanced disease. Oncol Res Treat 37:355-362, 2014

7. Hensley ML, Miller A, O'Malley DM, et al: Randomized phase III trial of gemcitabine plus docetaxel plus bevacizumab or placebo as first-line treatment for metastatic uterine leiomyosarcoma: An NRG Oncology/Gynecologic Oncology Group study. J Clin Oncol 33:1180-1185, 2015

8. Le Cesne A, Judson I, Crowther D, et al: Randomized phase III study comparing conventional-dose doxorubicin plus ifosfamide versus high-dose doxorubicin plus ifosfamide plus recombinant human granulocytemacrophage colony-stimulating factor in advanced soft tissue sarcomas: A trial of the European Organization for Research and Treatment of Cancer/Soft Tissue and Bone Sarcoma Group. J Clin Oncol 18:2676-2684, 2000

9. National Comprehensive Cancer Network: Guidelines for Treatment of Cancer. www.nccn.org/ professionals/physician_gls/f_guidelines.asp\#site

10. Maki RG, Wathen JK, Patel SR, et al: Randomized phase II study of gemcitabine and docetaxel compared with gemcitabine alone in patients with metastatic soft tissue sarcomas: Results of Sarcoma Alliance for Research Through Collaboration study 002 [corrected]. J Clin Oncol 25:2755-2763, 2007

11. Zucali PA, Bertuzzi $A$, Parra HJ, et al: The old drug dacarbazine as a second/third line chemotherapy in advanced soft tissue sarcomas. Invest New Drugs 26:175-181, 2008

12. Garcia-Del-Muro X, Lopez-Pousa A, Maurel J, et al: Randomized phase II study comparing gemcitabine plus dacarbazine versus dacarbazine alone in patients with previously treated soft tissue sarcoma: A Spanish Group for Research on Sarcomas study. J Clin Oncol 29:2528-2533, 2011

13. Ryan $C$, Schoffski $P$, Merimsky $O$, et al: PICASSO 3: A phase III international, randomized, double-blind, placebo-controlled study of doxorubicin (dox) plus palifosfamide (pali) vs. dox plus placebo for patients (pts) in first-line for metastatic soft tissue sarcoma (mSTS). Eur J Cancer S876, 2013 (abstr 3802)

14. Van Glabbeke M, Verweij J, Judson I, et al: Progression-free rate as the principal end-point for phase II trials in soft-tissue sarcomas. Eur $\mathrm{J}$ Cancer 38:543-549, 2002

15. Demetri GD, Chawla SP, von Mehren M, et al: Efficacy and safety of trabectedin in patients with 
advanced or metastatic liposarcoma or leiomyosarcoma after failure of prior anthracyclines and ifosfamide: Results of a randomized phase II study of two different schedules. J Clin Oncol 27:4188-4196, 2009

16. Sleijfer S, Ray-Coquard I, Papai Z, et al: Pazopanib, a multikinase angiogenesis inhibitor, in patients with relapsed or refractory advanced soft tissue sarcoma: A phase II study from the European Organisation for Research and Treatment of Cancer Soft Tissue and Bone Sarcoma Group (EORTC study 62043). J Clin Oncol 27:3126-3132, 2009

17. van der Graaf WT, Blay JY, Chawla SP, et al: Pazopanib for metastatic soft-tissue sarcoma (PALETTE): A randomized, double-blind, placebocontrolled, phase III trial. Lancet 379:1879-1886, 2012

18. Allavena $P$, Signorelli $M$, Chieppa $M$, et al: Antiinflammatory properties of the novel antitumor agent yondelis (trabectedin): Inhibition of macrophage differentiation and cytokine production. Cancer Res 65: 2964-2971, 2005

19. Germano G, Frapolli R, Belgiovine $C$, et al: Role of macrophage targeting in the antitumor activity of trabectedin. Cancer Cell 23:249-262, 2013

20. Germano G, Frapolli $R$, Simone $M$, et al: Antitumor and anti-inflammatory effects of trabectedin on human myxoid liposarcoma cells. Cancer Res 70:2235-2244, 2010

21. Zewail-Foote $M$, Hurley LH: Ecteinascidin 743: A minor groove alkylator that bends DNA toward the major groove. J Med Chem 42: 2493-2497, 1999

22. D'Incalci $M$, Jimeno J: Preclinical and clinical results with the natural marine product ET-743. Expert Opin Investig Drugs 12:1843-1853, 2003

23. Yovine A, Riofrio M, Blay J, et al: Phase II study of Ecteinascidin-743 in advanced pretreated soft tissue sarcoma patients. J Clin Oncol 22:890-900, 2004

24. Le Cesne A, Blay JY, Judson I, et al: Phase II study of ET-743 in advanced soft tissue sarcomas: A European Organisation for the Research and Treatment of Cancer (EORTC) Soft Tissue and Bone Sarcoma Group trial. J Clin Oncol 23:576-584, 2005

25. Garcia-Carbonero R, Supko J, Manola J, et al: Phase II and pharmacokinetic study of Ecteinascidin743 in patients with progressive sarcomas of soft tissues refractory to chemotherapy. J Clin Oncol 22: 1480-1490, 2004

26. Chmielowski B, Federman N, Tap WD: Clinical trial end points for assessing efficacy of novel therapies for soft tissue sarcomas. Expert Rev Anticancer Ther 12:1217-1228, 2012

27. Dodd LE, Korn EL, Freidlin B, et al: An audit strategy for progression-free survival. Biometrics 67: 1092-1099, 2011

28. Grosso F, Jones RL, Demetri GD, et al: Efficacy of trabectedin (Ecteinascidin-743) in advanced pretreated myxoid liposarcomas: A retrospective study. Lancet Oncol 8:595-602, 2007

29. Takahashi S, Araki N, Sugiura $H$, et al: A randomized phase II study comparing trabectedin (T) and best supportive care (BSC) in patients (pts) with translocation-related sarcomas (TRS). J Clin Oncol 32:674s, 2014 (abstr 10524)

30. Yonemoto T, Takahashi S, Araki N, et al: Intraand inter-patient comparison of efficacy between two phase II studies of trabectedin (T) in patients (PTS) with translocation-related sarcomas (TRS); A randomized comparative study (Study-C) and a single arm study (Study-S). Ann Oncol 25:iv498, 2014

31. Forni $C$, Minuzzo M, Virdis E, et al: Trabectedin (ET-743) promotes differentiation in myxoid liposarcoma tumors. Mol Cancer Ther 8: 449-457, 2009
32. Di Giandomenico S, Frapolli R, Bello E, et al: Mode of action of trabectedin in myxoid liposarcomas. Oncogene 33:5201-5210, 2014

33. Grohar PJ, Segars LE, Yeung C, et al: Dual targeting of EWS-FLI1 activity and the associated DNA damage response with trabectedin and SN38 synergistically inhibits Ewing sarcoma cell growth. Clin Cancer Res 20:1190-1203, 2014

34. Le Cesne A, Blay JY, Domont J, et al: Interruption versus continuation of trabectedin in patients with soft-tissue sarcoma (T-DIS): A randomized phase II trial. Lancet Oncol 16:312-319, 2015

35. Le Cesne A, Yovine A, Blay J-Y, et al: A retrospective pooled analysis of trabectedin safety in 1,132 patients with solid tumors treated in phase II clinical trials. Invest New Drugs 30:1193-1202, 2012

36. Le Cesne A, Ray-Coquard I, Duffaud F, et al: Trabectedin in patients with advanced soft tissue sarcoma: A retrospective national analysis of the French Sarcoma Group. Eur J Cancer 51:742-750, 2015

37. Martin-Liberal J, Judson I: Safety evaluation of trabectedin in treatment of soft-tissue sarcomas. Expert Opin Drug Saf 12:905-911, 2013

38. Leporini $C$, Patanè $M$, Saullo $F$, et al: A comprehensive safety evaluation of trabectedin and drugdrug interactions of trabectedin-based combinations. BioDrugs 28:499-511, 2014

39. Nielsen OS, Judson I, van Hoesel Q, et al: Effect of high-dose ifosfamide in advanced soft tissue sarcomas: A multicentre phase II study of the EORTC Soft Tissue and Bone Sarcoma Group. Eur J Cancer 36:61-67, 2000

40. Le Cesne A, Judson I, Maki R, et al: Trabectedin is a feasible treatment for soft tissue sarcoma patients regardless of patient age: $A$ retrospective pooled analysis of five phase $\mathrm{II}$ trials. $\mathrm{Br}$ J Cancer 109:1717-1724, 2013

George D. Demetri, Dana-Farber Cancer Institute and Ludwig Center at Harvard, Boston, MA; Margaret von Mehren, Fox Chase Cancer Center; Arthur Staddon, University of Pennsylvania, Philadelphia; Hussein Tawbi, University of Pittsburgh Cancer Institute, Pittsburgh, PA; Robin L. Jones, Seattle Cancer Care Alliance, Seattle, WA; Martee L. Hensley, Memorial Sloan Kettering Cancer Center; Robert G. Maki, Mount Sinai Medical Center, New York, NY; Scott M. Schuetze, University of Michigan, Ann Arbor, MI; Mohammed Milhem, University of Iowa Hospitals and Clinics, Iowa City, IA; Anthony Elias, University of Colorado Cancer Center, Aurora, CO; Kristen Ganjoo, Stanford Hospital and Clinics, Stanford, CA; Brian A. Van Tine, Washington University in St Louis, St Louis, MO; Alexander Spira, Virginia Cancer Specialists, Fairfax, VA; Andrew Dean, St John of God Hospital-Bendat Cancer Centre, Subiaco, Western Australia, Australia; Nushmia Z. Khokhar, Youn Choi Park, Roland E. Knoblauch, and Trilok V. Parekh, Janssen Research \& Development, Raritan, NJ; and Shreyaskumar R. Patel, The University of Texas MD Anderson Cancer Center, Houston, TX. 


\section{AUTHORS' DISCLOSURES OF POTENTIAL CONFLICTS OF INTEREST}

Efficacy and Safety of Trabectedin or Dacarbazine for Metastatic Liposarcoma or Leiomyosarcoma After Failure of Conventional Chemotherapy: Results of a Phase III Randomized Multicenter Clinical Trial

The following represents disclosure information provided by authors of this manuscript. All relationships are considered compensated. Relationships are self-held unless noted. I = Immediate Family Member, Inst = My Institution. Relationships may not relate to the subject matter of this manuscript. For more information about ASCO's conflict of interest policy, please refer to www.asco.org/rwc or jco.ascopubs.org/site/ifc.

George D. Demetri

Stock or Other Ownership: Blueprint Medicines, Kolltan

Pharmaceuticals, G1 Therapeutics, Caris Life Sciences, N-of-One

Consulting or Advisory Role: Bayer, Janssen Pharmaceuticals,

GlaxoSmithKline, Sanofi, EMD Serono, Blueprint Medicines, Kolltan

Pharmaceuticals, G1 Therapeutics, Caris Life Sciences, ARIAD

Pharmaceuticals, Threshold Pharmaceuticals, Champions Oncology,

ZIOPHARM Oncology, WIRB-Copernicus Group, Polaris Group, Pfizer,

Novartis

Research Funding: Janssen Pharmaceuticals (Inst), Novartis (Inst), Pfizer

(Inst), Bayer (Inst), Threshold Pharmaceuticals (Inst), EMD Serono (Inst)

Expert Testimony: Janssen Pharmaceuticals

Margaret von Mehren

Consulting or Advisory Role: Janssen Pharmaceuticals

Robin L. Jones

Consulting or Advisory Role: Pfizer (Inst), IMS Consulting Group (Inst), The Dominion Group (Inst), EMD Serono (Inst), Novartis (Inst), Compass Oncology (Inst)

Research Funding: Janssen Pharmaceuticals (Inst)

Travel, Accommodations, Expenses: EMD Serono, Pfizer, Novartis,

Compass Oncology

Martee L. Hensley

Employment: Sanofi (I)

Consulting or Advisory Role: EMD Serono, INSYS Therapeutics, Janssen

Pharmaceuticals, Natera

Research Funding: Janssen Pharmaceuticals (Inst)

Patents, Royalties, Other Intellectual Property: UpToDate

Scott M. Schuetze

Consulting or Advisory Role: Janssen Pharmaceuticals, EMD Serono

Research Funding: Janssen Pharmaceuticals (Inst)

Travel, Accommodations, Expenses: Janssen Pharmaceuticals, EMD

Serono

\section{Arthur Staddon}

Research Funding: Janssen Pharmaceuticals (Inst)

Mohammed Milhem

Consulting or Advisory Role: EMD Serono, Novartis

Travel, Accommodations, Expenses: EMD Serono, Novartis

\section{Anthony Elias}

Consulting or Advisory Role: Genentech

Research Funding: Medivation (Inst), Astellas Pharma (Inst), Genentech (Inst), Incyte (Inst), CytRx (Inst), Eisai (Inst), Johnson \& Johnson (Inst), Imclone Systems (Inst)

Travel, Accommodations, Expenses: Genentech

Kristen Ganjoo

No relationship to disclose

\section{Hussein Tawbi}

No relationship to disclose

Brian A. Van Tine

Consulting or Advisory Role: Advaxis, GlaxoSmithKline, Eli Lilly, ImClone Systems, EMD Serono, Johnson \& Johnson, Caris Life Sciences, DFINE, Threshold Pharmaceuticals, Novartis

Speakers' Bureau: GlaxoSmithKline, Caris Life Sciences, DFINE Research Funding: Polaris Group, Morphotek

\section{Alexander Spira}

No relationship to disclose

\section{Andrew Dean}

Honoraria: Gilead Sciences, Specialised Therapeutics Australia Consulting or Advisory Role: AstraZeneca (Inst)

Speakers' Bureau: Novartis

Travel, Accommodations, Expenses: Boehringer Ingelheim

\section{Nushmia Z. Khokhar}

Employment: Janssen Pharmaceuticals

Stock or Other Ownership: Johnson \& Johnson

\section{Youn Choi Park}

Employment: Janssen Pharmaceuticals

Stock or Other Ownership: Johnson \& Johnson

\section{Roland E. Knoblauch}

Employment: Janssen Pharmaceuticals

Stock or Other Ownership: Johnson \& Johnson

Patents, Royalties, Other Intellectual Property: Use of phenformin for the treatment of cancer

Trilok V. Parekh

Employment: Janssen Pharmaceuticals

Stock or Other Ownership: Johnson \& Johnson

\section{Robert G. Maki}

Consulting or Advisory Role: Bayer HealthCare Pharmaceuticals, Eisai, Eli Lilly, Gem Pharmaceuticals, GlaxoSmithKline, SARC: Sarcoma Alliance for Research through Collaboration, TRACON Pharmaceuticals Speakers' Bureau: Bayer

Research Funding: Eisai (Inst), TRACON Pharmaceuticals (Inst), Eli Lilly (Inst)

Patents, Royalties, Other Intellectual Property: UpToDate

Travel, Accommodations, Expenses: Bayer, Onyx Pharmaceuticals, Janssen Pharmaceuticals

\section{Shreyaskumar R. Patel}

Consulting or Advisory Role: Janssen Pharmaceuticals, Novartis, CytRx, EMD-Serono

Research Funding: Janssen Pharmaceuticals (Inst), Morphotek (Inst), Eisai (Inst) 


\section{Acknowledgment}

We thank the investigators and coordinators at each of the clinical sites; the patients who volunteered to participate in this study and their families; the sponsor staff involved in data collection and analyses; Namit Ghildyal, $\mathrm{PhD}$, for editorial assistance in the development of the manuscript; and the Adelson Medical Research Foundation for partial support of this research (to G.D.D.). The academic authors had complete access to all data and maintained control over the manuscript, including final wording and conclusions.

\section{Appendix}

The following additional investigators, listed in alphabetical order, participated in the SAR-3007 study: Australia—W. Joubert (Woolloongabba, Queensland), C. Lewis (Randwick, New South Wales), G. Richardson (Malvern, Victoria); Brazil—V. Dybal (Salvador, Bahia), R. Schmerling (São Paulo, São Paulo), S.V. Serrano (Barretos, São Paulo), L. Viola (Porto Alegre, Rio Grande do Sul); New Zealand-A. O'Donnell (Wellington), D. Porter (Auckland); United States-A. Aboulafia (Baltimore, MD), M. Agulnik (Chicago, IL), M. Auber (Morgantown, WV), J. Ayers formerly L. Horvath (Warrenville, IL), M. Batus (Chicago, IL), A. Bhinder (Columbus, OH), J. Burke (Savannah, GA), J. Charlson (Milwaukee, WI), C. Cowey (Dallas, TX), L. Cranmer (Tucson, AZ), S. Dakhil (Wichita, KS), G. D'Amato (Atlanta, GA), T. Davis (Lebanon, NH), H.M.D. Deshpande (New Haven, CT), G. FernandezCastro (Miami, FL), C. Forscher (Los Angeles, CA), S. Ghamande (Augusta, GA), J. Gibbons (Cleveland, OH), R. Gollard (Las Vegas, NV), R. Govindarajan (Little Rock, AR), S. Gupta-Burt (Overland Park, KS), J. Hamm (Louisville, KY), W. Hanna (Knoxville, TN), W.G. Harker (Salt Lake City, UT), R. Harris (Johnson City, NY), H. Harvey (Hershey, PA), I. Hinshaw (Denver, CO), R. Holloway (Orlando, FL), K. Hotten-Leu (Omaha, NE), A. Hussein (Hollywood, FL), S. Jaggernauth (Tulsa, OK), P. Kaiser (Park Ridge, IL), K. Kalinsky (New York, NY), A. Karnad (San Antonio, TX), S. Karri (Dallas, TX), V. Keedy (Nashville, TN), H. Koh (Bellflower, CA), A. Kraft (Charleston, SC), N. Le-Lindqwister (Peoria, IL), M. Livingston (Charlotte, NC), P. Mansky (Green Bay, WI), S. McMeekin (Oklahoma City, OK), C. Meyer (Baltimore, MD), B. Monk (Phoenix, AZ), K. Mulvey (Post Falls, ID), M. Myron (Overland Park, KS), B. Piperdi (New York, NY), L. Pliner (Newark, NJ), D. Reed (Tampa, FL), G. Rosen (New York, NY), D. Rushing (Indianapolis, IN), C. Ryan (Portland, OR), J. Sandbach (Austin, TX), M. Seetharam (Phoenix, AZ), R. Seth (Syracuse, NY), M. Shaheen (Albuquerque, NM), R. Siegel (Hartford, CT), A. Singh (Santa Monica, CA), G. Srkalovic (Lansing, MI), S. Tejwani (Detroit, MI), S. Thomas (Orlando, FL), S. Undevia (Naperville, IL).

\begin{tabular}{|c|c|c|}
\hline \multirow[b]{2}{*}{ Cycle or Dose Variable } & \multicolumn{2}{|c|}{ No. $(\%)$ of Patients } \\
\hline & Trabectedin $(n=340)$ & Dacarbazine $(n=155$ \\
\hline Total with at least two cycles & $298(88)$ & $125(81)$ \\
\hline \multicolumn{3}{|l|}{ Cycle delay } \\
\hline Yes & $193(57)$ & $62(40)$ \\
\hline No & $105(31)$ & $63(41)$ \\
\hline \multicolumn{3}{|l|}{ No. of cycle delays } \\
\hline 1 & $96(28)$ & $35(23)$ \\
\hline 2 & $37(11)$ & $13(8)$ \\
\hline 3 & $27(8)$ & $8(5)$ \\
\hline 4 & $12(4)$ & $1(1)$ \\
\hline$\geq 5$ & $21(6)$ & $5(3)$ \\
\hline \multicolumn{3}{|l|}{ Dose reduction } \\
\hline Yes & 119 (35) & $15(10)$ \\
\hline No & $179(53)$ & $110(71)$ \\
\hline \multicolumn{3}{|l|}{ No. of dose reductions } \\
\hline 1 & $83(24)$ & $13(8)$ \\
\hline 2 & $36(11)$ & $2(1)$ \\
\hline
\end{tabular}

